\section{Descripción del ambiente laboral de un grupo de mujeres trabajadoras de intendencia en una institución pública}

Villanueva Becerril, 0

Escuela Superior de Medicina, Instituto Politécnico Nacional, Ciudad de México, México. e-mail: ovillanu@ipn.mx.

PALAVRAS-CHAVE: Subcontratación, Feminismo, Discriminación, Bioética

El incremento constante del uso de tecnologías para la producción de bienes y servicios de consumo masivo ha generado transformaciones en la manera en la que se organiza el trabajo. La optimización constante de los procesos plantea que los salarios de los trabajadores representan una carga para la competitividad de las empresas en mercados cada vez más controlados. Bajo esta premisa se han creado corporaciones que proveen mano de obra para labores consideradas poco especializadas en las que predominan las bajas remuneraciones y malas condiciones laborales (1). Las plazas de este tipo son ocupadas principalmente por mujeres que comparten ciertas particularidades. El discurso del proceso bioético considera que se trata de discriminación (2). El objetivo de esta investigación es analizar cómo se desarrolla la referida discriminación, en el ambiente laboral, de un grupo de mujeres empleadas por una compañía operada bajo el esquema de subcontratación para realizar labores de limpieza en una institución pública de educación superior a partir de su género, edad, posición social, nivel educativo y fenotipo. La metodología de la investigación es de tipo cualitativo. La elección se fundamenta en la postura teórico-metodológica de la bioética feminista puesto que son fundamentalmente mujeres quienes acceden a estos puestos de trabajo. Esta perspectiva permite vincular las subjetividades del grupo de mujeres con expresiones como la escolaridad, la edad, el aspecto físico o el uso del lenguaje que, en conjunto, conforman la discriminación (5). El método etnográfico facilita las herramientas para establecer un diálogo con el grupo de mujeres del estudio que permita construir una estructura de significados en su contexto. Los hallazgos muestran que la discriminación hacia el grupo de mujeres es un fenómeno complejo en el que intervienen distintas determinantes que se complementan en diversos modos y grados. Entre estas expresiones se adopta, por su carácter colectivo, la construcción histórica de la subjetividad de las trabajadoras, con relación a la figura tradicional de ser mujermadre en la cultura mexicana, como eje para elaborar un esquema de la discriminación (4). Se describen las relaciones de los valores, representados en el proceso pensamientoacción, de estas mujeres con su clase social, su edad, su grado de estudios y su apariencia física. Así también se narra la articulación de la ideología de la entrega a los "otros" con el principio de la maximización de las ganancias del sistema económico dominante mediante el mecanismo del abandono personal e institucional. De este modo, la discriminación que sufren, en el ambiente laboral, las mujeres del estudio constituye un proceso desarrollado a lo largo del tiempo en el que la subordinación social y psicológica son determinantes (3). Esta situación contradice el discurso de afirmación de los Derechos Humanos y, para este caso, la bioética puede proponer una vía de transformación de los principios de responsabilidad, libertad y solidaridad con miras a construir una realidad diferente para ellas.

AGRADECIMENTOS. Dra. Rocío Fuentes Valdivieso, Programa de Maestría en Ciencias en Bioética e Instituto Politécnico Nacional.

REFERÊNCIAS Durand JP. La cadena invisible. Flujo tenso y servidumbre voluntaria. Ciudad de México: Fondo de Cultura Económica., Universidad Autónoma Metropolitana; 2011.

[2] Engelhardt TH. Los Fundamentos de bioética Barcelona: Paidós; 1995.

[3] Scott JW. Género e Historia México: Fondo de Cultura Económica; 2012.

[4] Lagarde M. Los cautiverios de la mujeres: madresposas,monjas, putas, presas y locas México: Universidad Nacional Autónoma de México; 2011.

[5] Lamas M. Cuerpo: Diferencia sexual y género México, D.F.: Taurus; 2002. 